\title{
Failure of thrombolysis by streptokinase: detection with a simple electrocardiographic method
}

\author{
A G C Sutton, P G Campbell, D J A Price, E D Grech, J A Hall, A Davies, M J Stewart,
} M A de Belder

\begin{abstract}
Objective-To determine whether simple, readily applicable ECG criteria will allow early prediction of inadequate (< TIMI 3) flow in the infarct related vessel in patients receiving thrombolytic treatment for acute myocardial infarction; and to determine the success of streptokinase in achieving adequate antegrade flow in the infarct related vessel two hours after starting treatment.

Design-Cohort study.

Setting-Regional cardiothoracic unit.

Patients-100 sequential patients with acute myocardial infarction.

Interventions-Coronary angiography two hours after the initiation of thrombolytic treatment, proceeding to rescue angioplasty for inadequate flow in the infarct related vessel where appropriate.

Main outcome measures-Sensitivity, specificity, positive predictive value, negative predictive value, and accuracy of six ECG criteria for the detection of inadequate antegrade flow in the infarct related vessel.

Results-The ECG test that performed best as a positive test for < TIMI 3 flow in the infarct related vessel was $<50 \%$ resolution of the ST segment elevation in the worst lead and no accelerated idioventricular rhythm. This had a sensitivity of $81 \%$, specificity of $88 \%$, positive predictive value of $87 \%$, negative predictive value of $83 \%$, and overall accuracy of $85 \%$.

Conclusions-Sensitive, specific, and simple ECG criteria are defined for diagnosing failure of thrombolytic treatment with streptokinase. These allow the early detection of patients at high risk of further adverse events from a persistently occluded vessel. They may be used without recourse to sophisticated equipment or complex analyses. Such patients can then be considered for alternative treatments or enrolment into appropriate research protocols.

(Heart 2000;84:149-156)
\end{abstract}

Keywords: myocardial infarction; thrombolysis; streptokinase

Intravenous thrombolysis plus aspirin is the most widely used treatment for patients presenting in the acute phase of myocardial infarction. Thombolytic treatment prevents approximately 20-30 deaths per 1000 patients treated, with a proportional reduction in mortality of up to $25 \%$ in certain subgroups. ${ }^{1}$ However, thrombolysis is not always successful. In the angiographic substudy of the GUSTO-I trial, the 90 minute arterial patency rate (defined by the presence of TIMI grade 2 or 3 flow) was $54 \%$ in patients who received streptokinase, with only $29 \%$ of patients having desirable TIMI grade 3 flow. ${ }^{2}{ }^{3}$ Accelerated tissue plasminogen activator, the thrombolytic regimen that yields superior early flow rates, still produced TIMI 3 flow in only $54 \%$ of patients. Failure to achieve arterial patency following thrombolytic treatment is associated with a poor outcome. Therefore, simple non-invasive methods are desirable in order to detect patients with failed thrombolysis at an early stage, so that alternative strategies can be considered before irreversible myocardial necrosis occurs. Alternative methods include the repeated use of thrombolytic agents, rescue angioplasty, or even emergency coronary artery bypass surgery.

Several studies have examined the use of specific ECG criteria as markers of inadequate arterial flow in the infarct related vessel, but many have design flaws and others describe methods that are currently impractical in busy coronary care units (CCUs).

The objectives of this study were to correlate the findings at coronary angiography with the ECG findings two hours after the onset of thrombolytic treatment in order to determine whether simple ECG formulae could be used to identify patients with persistent arterial occlusion prospectively and non-invasively. A further objective was to assess the efficacy of thrombolytic treatment in these patients.

\section{Methods}

Over a 14 month period starting in August 1997 , a consecutive series of 100 patients presenting to our CCU within 10 hours of the onset of acute myocardial infarction was studied. Acute myocardial infarction was identified by the onset of typical chest pain lasting more than 30 minutes, unrelieved by sublingual nitrate, and associated with typical ST segment elevation on the standard 12 lead ECG.

The following factors were exclusion criteria: cardiogenic shock; contraindication to thrombolysis; confounding features on the pretreatment ECG (for example, bundle branch block); no femoral arterial access; pregnancy; inability to give fully informed consent. 
Absolute contraindications to thrombolysis in this study were: active bleeding; gastrointestinal bleeding within the last three months; uncontrolled hypertension (systolic blood pressure of greater than $200 \mathrm{~mm} \mathrm{Hg}$ on repeated measurement); any history of coagulopathy or bleeding diathesis, including warfarin treatment; cerebrovascular accident within the last six months; any previous history of confirmed intracerebral haemorrhage; major surgery or significant trauma within the last 10 days, including prolonged cardiopulmonary resuscitation; and proliferative (but not background) diabetic retinopathy.

The local ethics committee approved the study. All patients gave informed and written consent.

\section{DRUG ADMINISTRATION}

Streptokinase was given in the standard dose of $1.5 \times 10^{6}$ units over 60 minutes. All patients except one received aspirin. Other drug treatment was prescribed at the discretion of the attending cardiologist.

ECG ANALYSIS

An ECG was recorded just before starting the streptokinase infusion and immediately before coronary angiography two hours later. The second ECG was recorded immediately before coronary angiography in the cardiac catheterisation laboratory. The following measurements on each ECG were recorded: ST segment elevation in the lead with the maximum ST segment elevation ("worst lead") before thrombolytic treatment; the summed ST segment elevation in all leads reflecting the infarct zone; the peak of the $\mathrm{T}$ wave in the worst lead; the summed peaks of the $T$ waves in all leads reflecting the infarct zone; and the presence of an accelerated idioventricular rhythm on the two hour ECG. ST segments were analysed $80 \mathrm{~ms}$ after the J point. Six ECG criteria were used to predict inadequate flow in the infarct related vessel. Inadequate flow was defined first by < TIMI 3 flow, and second by < TIMI 2 flow. The criteria used are shown below.

(1) Less than $50 \%$ resolution of the ST segment elevation in the worst lead and no accelerated idioventricular rhythm two hours after the initiation of thrombolytic treatment.

(2) Less than $70 \%$ resolution of the ST segment elevation in the worst lead and no accelerated idioventricular rhythm two hours after the initiation of thrombolytic treatment.

(3) Less than $30 \%$ resolution of the ST segment elevation in the worst lead and no accelerated idioventricular rhythm two hours after the initiation of thrombolytic treatment.

(4) Less than $50 \%$ reduction of the $\mathrm{T}$ wave peak in the worst lead and no accelerated idioventricular rhythm two hours after the initiation of thrombolytic treatment.

(5) Less than $50 \%$ resolution of the summed ST segment elevation in the leads reflecting the infarct zone and no accelerated idi-
Table 1 TIMI flow in the infarct related vessel ${ }^{4}$

\begin{tabular}{ll}
$\begin{array}{l}\text { Grade of } \\
\text { TIMI flow }\end{array}$ & Definition \\
\hline 0 & $\begin{array}{l}\text { Complete occlusion } \\
\text { Penetration without perfusion. Coronary bed } \\
\text { distal to the occlusion fails to opacify completely }\end{array}$ \\
2 & $\begin{array}{l}\text { Partial perfusion. Full but slow opacification of } \\
\text { the coronary bed distal to the occlusion }\end{array}$ \\
3 & Complete perfusion
\end{tabular}

TIMI, thrombolysis in myocardial infarction trial.

oventricular rhythm two hours after the initiation of thrombolytic treatment.

(6) Less than $50 \%$ resolution of the summed $\mathrm{T}$ wave peaks in the leads reflecting the infarct zone and no accelerated idioventricular rhythm two hours after the initiation of thrombolytic treatment.

The ECG criteria were selected following a review of published reports, with particular emphasis on criteria that could be measured quickly and without recourse to specialised equipment. All the prespecified criteria were measured in all the patients where possible, and we tested no other criteria apart from those described here.

\section{CORONARY ANGIOGRAM ANALYSIS}

Coronary angiography was performed through the right femoral artery two hours after the initiation of thrombolytic treatment. Flow in the infarct related vessel was quantified according to the TIMI classification ${ }^{4}$ (table 1 ).

\section{STATISTICAL METHODS}

The aim of the diagnostic method was the detection of failure of thrombolysis, defined by the presence of $<$ TIMI grade 3 flow in the infarct related vessel. Accordingly, the sensitivity of the test is a measure of the ability of the test to detect genuine cases of failed reperfusion (that is, the number of cases with failed reperfusion on ECG and at angiography, as a proportion of all cases of failed reperfusion at angiography). The specificity of the test is a measure of the ability of the test to detect genuine cases of successful reperfusion (that is, the number of cases with successful reperfusion detected by the ECG criteria and at angiography, as a proportion of all cases of successful reperfusion at angiography). The positive predictive value (PPV) is the proportion of patients with a positive ECG test who have failed reperfusion at angiography. The negative predictive value (NPV) is the proportion of patients with a negative ECG test who have successful reperfusion at coronary

Table 2 Demographic details of enrolled patients

\begin{tabular}{ll}
\hline & Number $(n=100)$ \\
\hline Men & 62 \\
Women & 38 \\
Age range (years) & $37-86$ \\
Mean (SD) age (years) & $63.3(11.8)$ \\
Diabetes & 8 \\
Hypertension & 22 \\
Smoker & 50 \\
Ex-smoker & 29 \\
Hypercholesterolaemia $^{\star}$ & 75
\end{tabular}

$\star$ Defined by a random cholesterol on admission of $>5.2 \mathrm{mmol} / 1$ or if the patient was taking a lipid lowering agent. 
Table 3 Numbers of patients fulfilling positive (test + ) and negative (test - ) ECG criteria with < TIMI 3 or TIMI 3 flow in the infarct related vessel

\begin{tabular}{|c|c|c|c|}
\hline & & $T I M I<3$ & TIMI 3 \\
\hline Criterion 1 & $\begin{array}{l}\text { Test }+ \\
\text { Test }-\end{array}$ & $\begin{array}{c}39 \text { (RCA 19, LAD 15) } \\
9 \text { (RCA 6, LAD 2) }\end{array}$ & $\begin{array}{c}6(\text { RCA 3, LAD 3) } \\
45(\text { RCA 18, LAD 17) }\end{array}$ \\
\hline Criterion 2 & $\begin{array}{l}\text { Test }+ \\
\text { Test - }\end{array}$ & $\begin{array}{l}44 \text { (RCA 22, LAD 17) } \\
4 \text { (RCA 3, LAD 0) }\end{array}$ & $\begin{array}{l}19 \text { (RCA 9, LAD 7) } \\
32(\text { RCA 12, LAD 13) }\end{array}$ \\
\hline Criterion 3 & $\begin{array}{l}\text { Test }+ \\
\text { Test - }\end{array}$ & $\begin{array}{l}33 \text { (RCA 16, LAD 12) } \\
15 \text { (RCA 9, LAD 5) }\end{array}$ & $\begin{array}{c}6 \text { (RCA 3, LAD 3) } \\
45 \text { (RCA 18, LAD 17) }\end{array}$ \\
\hline Criterion 4 & $\begin{array}{l}\text { Test }+ \\
\text { Test }-\end{array}$ & $\begin{array}{l}38 \text { (RCA 21, LAD 12) } \\
10 \text { (RCA 4, LAD 5) }\end{array}$ & $\begin{array}{l}11 \text { (RCA 5, LAD 4) } \\
40 \text { (RCA 16, LAD 16) }\end{array}$ \\
\hline Criterion 5 & $\begin{array}{l}\text { Test }+ \\
\text { Test - }\end{array}$ & $\begin{array}{c}39 \text { (RCA 20, LAD 14) } \\
9 \text { (RCA 5, LAD 3) }\end{array}$ & $\begin{array}{c}9 \text { (RCA 5, LAD 3) } \\
42 \text { (RCA 16, LAD 17) }\end{array}$ \\
\hline Criterion 6 & $\begin{array}{l}\text { Test }+ \\
\text { Test }-\end{array}$ & $\begin{array}{c}42 \text { (RCA 21, LAD 15) } \\
6 \text { (RCA 4, LAD 2) }\end{array}$ & $\begin{array}{l}11 \text { (RCA 5, LAD 3) } \\
40(\text { RCA } 16, \text { LAD } 17)\end{array}$ \\
\hline
\end{tabular}

$\mathrm{n}=99$ (one patient excluded because of left bundle branch block at two hours).

$\mathrm{LAD}$, left anterior descending coronary artery; RCA, right coronary artery.

angiography. The overall accuracy of the test is the number of patients in whom the ECG test correctly predicted the angiographic findings as a proportion of the whole study group.

RESCUE ANGIOPLASTY

In the presence of an occlusion or an identifiable culprit coronary artery lesion at coronary angiography with < TIMI 3 flow, the patient was considered for rescue angioplasty. This was not routinely performed in the presence of TIMI 3 flow, but could be performed if the operator considered the risk of reocclusion to be excessive. The patient consented to rescue angioplasty before the start of the catheter laboratory procedure. Standard interventional techniques and materials were used. The use of stents, the glycoprotein IIb/IIIa inhibitor abciximab, and intra-aortic balloon counterpulsation was at the discretion of the attending cardiologist.

\section{Results}

During the period of enrolment, only one eligible patient refused to give consent to take part in the study. The demographic details of enrolled patients are shown in table 2. Initial ECG analysis resulted in the diagnosis of acute inferior myocardial infarction (34), anterior myocardial infarction (39), acute inferoposterior myocardial infarction (15), acute anterolateral myocardial infarction (7), acute inferolateral myocardial infarction (4), and acute lateral myocardial infarction (1). The worst lead on the initial ECG was II (3), III (44), aVf (5), V2 (21), V3 (17), V4 (4), V5 (5), and V6 (1). The infarct related lesion was in the right coronary artery (46), left anterior descending coronary artery (37), circumflex coronary artery (9), obtuse marginal branch (2), left main stem (1), diagonal (3), saphenous vein graft to right coronary artery (1), and in one patient was a bifurcating lesion into a large obtuse marginal branch from the circumflex artery. Paired ECG analysis was possible in 99 of the 100 patients. One patient with TIMI 3 flow at angiography had developed left bundle branch block (LBBB) by the time of the two hour ECG, making further ECG analysis impossible.

ECG CRITERIA FOR INADEQUATE ANTEGRADE FLOW AND FINDINGS AT CORONARY ANGIOGRAPHY

Table 3 shows the numbers of patients fulfilling each of the ECG criteria for inadequate (< TIMI 3) antegrade flow or adequate (TIMI 3) flow, together with the grade of TIMI flow at angiography. Shown in brackets are the equivalent numbers for patients with the right coronary artery and the left anterior descending coronary artery as the infarct related vessel.

Table 4 shows the sensitivity, specificity, positive predictive value, negative predictive value, and overall accuracy of all the ECG criteria for inadequate antegrade flow, defined by $<$ TIMI 3 flow. Values for the left anterior descending coronary artery and right coronary artery as the infarct related vessel are also shown. The only ECG test for detecting < TIMI 3 flow with a sensitivity, specificity,

Table 4 Sensitivity, specificity, positive predictive value, negative predictive value, and accuracy of each ECG test as a marker for < TIMI 3 flow

\begin{tabular}{|c|c|c|c|c|c|}
\hline $\begin{array}{l}\text { Positive test for }<\text { TIMI } 3 \\
\text { flow }\end{array}$ & Sensitivity (\%) & Specificity (\%) & $P P V(\%)$ & $N P V(\%)$ & Accuracy (\%) \\
\hline Criterion 1 & $\begin{array}{l}81 \\
\text { (RCA 76) } \\
\text { (LAD 88) }\end{array}$ & $\begin{array}{l}88 \\
\text { (RCA 86) } \\
\text { (LAD 85) }\end{array}$ & $\begin{array}{l}87 \\
\text { (RCA 86) } \\
\text { (LAD 83) }\end{array}$ & $\begin{array}{l}83 \\
\text { (RCA 75) } \\
\text { (LAD 89) }\end{array}$ & $\begin{array}{l}85 \\
\text { (RCA 80) } \\
\text { (LAD 86) }\end{array}$ \\
\hline Criterion 2 & $\begin{array}{l}92 \\
\text { (RCA 88) } \\
\text { (LAD 100) }\end{array}$ & $\begin{array}{l}63 \\
\text { (RCA 57) } \\
\text { (LAD 65) }\end{array}$ & $\begin{array}{l}70 \\
\text { (RCA 71) } \\
(\text { LAD 71) }\end{array}$ & $\begin{array}{l}89 \\
\text { (RCA 80) } \\
\text { (LAD 100) }\end{array}$ & $\begin{array}{l}77 \\
\text { (RCA 74) } \\
\text { (LAD 81) }\end{array}$ \\
\hline Criterion 3 & $\begin{array}{l}69 \\
\text { (RCA 64) } \\
(\text { LAD 71) }\end{array}$ & $\begin{array}{l}88 \\
\text { (RCA 86) } \\
\text { (LAD 85) }\end{array}$ & $\begin{array}{l}85 \\
\text { (RCA 84) } \\
\text { (LAD 80) }\end{array}$ & $\begin{array}{l}75 \\
\text { (RCA 67) } \\
\text { (LAD 77) }\end{array}$ & $\begin{array}{l}79 \\
\text { (RCA 74) } \\
\text { (LAD 78) }\end{array}$ \\
\hline Criterion 4 & $\begin{array}{l}79 \\
\text { (RCA 84) } \\
\text { (LAD 71) }\end{array}$ & $\begin{array}{l}78 \\
\text { (RCA 76) } \\
\text { (LAD 80) }\end{array}$ & $\begin{array}{l}78 \\
\text { (RCA 81) } \\
\text { (LAD 75) }\end{array}$ & $\begin{array}{l}80 \\
\text { (RCA 80) } \\
\text { (LAD 76) }\end{array}$ & $\begin{array}{l}79 \\
\text { (RCA 80) } \\
\text { (LAD 76) }\end{array}$ \\
\hline Criterion 5 & $\begin{array}{l}81 \\
\text { (RCA 80) } \\
\text { (LAD 82) }\end{array}$ & $\begin{array}{l}82 \\
\text { (RCA 76) } \\
\text { (LAD 85) }\end{array}$ & $\begin{array}{l}81 \\
\text { (RCA 80) } \\
\text { (LAD 82) }\end{array}$ & $\begin{array}{l}82 \\
\text { (RCA 76) } \\
\text { (LAD 85) }\end{array}$ & $\begin{array}{l}82 \\
\text { (RCA 78) } \\
\text { (LAD 84) }\end{array}$ \\
\hline Criterion 6 & $\begin{array}{l}88 \\
\text { (RCA 84) } \\
\text { (LAD 88) }\end{array}$ & $\begin{array}{l}78 \\
\text { (RCA 76) } \\
\text { (LAD 85) }\end{array}$ & $\begin{array}{l}79 \\
\text { (RCA 81) } \\
\text { (LAD 83) }\end{array}$ & $\begin{array}{l}87 \\
\text { (RCA 80) } \\
\text { (LAD 89) }\end{array}$ & $\begin{array}{l}83 \\
\text { (RCA 80) } \\
\text { (LAD 86) }\end{array}$ \\
\hline
\end{tabular}

$\mathrm{LAD}$, left anterior descending coronary artery; NPV, negative predictive value; PPV, positive presictive value; RCA, right coronary artery. 
Table 5 Numbers of patients fulfilling positive (test + ) and negative (test - ) ECG criteria with < TIMI 2 or TIMI 2 flow in the infarct related vessel

\begin{tabular}{llcl}
\hline & & TIMI <2 & TIMI 2 \\
\hline Criterion 1 & Test + & 32 (RCA 18, LAD 12) & 13 (RCA 4, LAD 6) \\
& Test - & 4 (RCA 3, LAD 0) & 50 (RCA 21, LAD 19) \\
Criterion 2 & Test + & 34 (RCA 20, LAD 12) & 29 (RCA 11, LAD 12) \\
& Test - & 2 (RCA 1, LAD 0) & 34 (RCA 14, LAD 13) \\
Criterion 3 & Test + & 28 (RCA 15, LAD 11) & 11 (RCA 4, LAD 4) \\
& Test - & 8 (RCA 6, LAD 1) & 52 (RCA 21, LAD 21) \\
Criterion 4 & Test + & 33 (RCA 20, LAD 10) & 16 (RCA 6, LAD 6) \\
& Test - & 3 (RCA 1, LAD 2) & 47 (RCA 19, LAD 19) \\
Criterion 5 & Test + & 32 (RCA 18, LAD 12) & 16 (RCA 7, LAD 5) \\
& Test - & 4 (RCA 3, LAD 0) & 47 (RCA 18, LAD 20) \\
Criterion 6 & Test + & 35 (RCA 20, LAD 12) & 18 (RCA 6, LAD 6) \\
& Test - & 1 (RCA 1, LAD 0) & 45 (RCA 19, LAD 19) \\
\hline
\end{tabular}

$\mathrm{n}=99$ (one patient excluded because of left bundle block at two hours).

positive predictive value, negative predictive value, and accuracy all $>80 \%$ was $<50 \%$ ST segment resolution in the worst lead and no accelerated idioventricular rhythm on the two hour ECG (that is, criterion 1). This measurement of the ST segment was also the easiest to perform.

We also looked at the numbers of patients fulfilling each of the ECG criteria for inadequate antegrade flow, with their angiographic findings, when inadequate antegrade flow was defined as < TIMI 2 flow (table 5). There were fewer false negative results and more false positive results for all ECG criteria with this definition of inadequate antegrade flow. Therefore the same ECG criteria have improved sensitivity and negative predictive values for $<$ TIMI 2 flow, but at the expense of a reduction in specificity and positive predictive value (table 6 ).

Analyses of patients with the left anterior descending coronary artery and right coronary artery as the infarct related vessels should be interpreted with caution given the small numbers, but show that the sensitivity and negative predictive value of our best ECG test for $<$ TIMI 3 are superior for patients with acute myocardial infarction in the left anterior

Table 6 Sensitivity, specificity, positive predictive value, negative predictive value, and accuracy of each ECG test as a marker for < TIMI 2 flow

\begin{tabular}{|c|c|c|c|c|c|}
\hline $\begin{array}{l}\text { Positive test for } \\
<\text { TIMI } 2 \text { flow }\end{array}$ & $\begin{array}{l}\text { Sensitivity } \\
(\%)\end{array}$ & Specificity (\%) & $P P V(\%)$ & $N P V(\%)$ & Accuracy (\%) \\
\hline Criterion 1 & $\begin{array}{l}89 \\
(\text { RCA 86) } \\
(\text { LAD 100) }\end{array}$ & $\begin{array}{l}79 \\
\text { (RCA 84) } \\
\text { (LAD 76) }\end{array}$ & $\begin{array}{l}71 \\
\text { (RCA 82) } \\
\text { (LAD 67) }\end{array}$ & $\begin{array}{l}93 \\
\text { (RCA 88) } \\
\text { (LAD 100) }\end{array}$ & $\begin{array}{l}83 \\
(\text { RCA 80) } \\
(\text { LAD 84) }\end{array}$ \\
\hline Criterion 2 & $\begin{array}{l}94 \\
\text { (RCA 95) } \\
\text { (LAD 100) }\end{array}$ & $\begin{array}{l}54 \\
\text { (RCA 56) } \\
\text { (LAD 52) }\end{array}$ & $\begin{array}{l}54 \\
\text { (RCA 65) } \\
(\text { LAD 100) }\end{array}$ & $\begin{array}{l}94 \\
\text { (RCA 93) } \\
\text { (LAD 100) }\end{array}$ & $\begin{array}{l}69 \\
\text { (RCA 74) } \\
\text { (LAD 68) }\end{array}$ \\
\hline Criterion 3 & $\begin{array}{l}78 \\
\text { (RCA 71) } \\
\text { (LAD 92) }\end{array}$ & $\begin{array}{l}83 \\
\text { (RCA 84) } \\
\text { (LAD 84) }\end{array}$ & $\begin{array}{l}72 \\
\text { (RCA 79) } \\
\text { (LAD 73) }\end{array}$ & $\begin{array}{l}87 \\
\text { (RCA 78) } \\
\text { (LAD 95) }\end{array}$ & $\begin{array}{l}81 \\
\text { (RCA 78) } \\
\text { (LAD 86) }\end{array}$ \\
\hline Criterion 4 & $\begin{array}{l}92 \\
\text { (RCA 95) } \\
\text { (LAD 83) }\end{array}$ & $\begin{array}{l}75 \\
\text { (RCA 76) } \\
\text { (LAD 76) }\end{array}$ & $\begin{array}{l}67 \\
\text { (RCA 77) } \\
\text { (LAD 63) }\end{array}$ & $\begin{array}{l}94 \\
\text { (RCA 95) } \\
\text { (LAD 90) }\end{array}$ & $\begin{array}{l}81 \\
\text { (RCA 85) } \\
\text { (LAD 78) }\end{array}$ \\
\hline Criterion 5 & $\begin{array}{l}89 \\
\text { (RCA 86) } \\
\text { (LAD 100) }\end{array}$ & $\begin{array}{l}75 \\
\text { (RCA 72) } \\
\text { (LAD 80) }\end{array}$ & $\begin{array}{l}67 \\
\text { (RCA 72) } \\
\text { (LAD 71) }\end{array}$ & $\begin{array}{l}92 \\
\text { (RCA 86) } \\
\text { (LAD 100) }\end{array}$ & $\begin{array}{l}80 \\
\text { (RCA 78) } \\
\text { (LAD 86) }\end{array}$ \\
\hline Criterion 6 & $\begin{array}{l}97 \\
\text { (RCA 95) } \\
\text { (LAD 100) }\end{array}$ & $\begin{array}{l}71 \\
\text { (RCA 76) } \\
\text { (LAD 76) }\end{array}$ & $\begin{array}{l}66 \\
\text { (RCA 77) } \\
\text { (LAD 67) }\end{array}$ & $\begin{array}{l}98 \\
\text { (RCA 95) } \\
\text { (LAD 100) }\end{array}$ & $\begin{array}{l}81 \\
\text { (RCA 85) } \\
\text { (LAD 84) }\end{array}$ \\
\hline
\end{tabular}

descending territory than in the right coronary territory. Considering TIMI 3 flow as adequate antegrade flow (table 3 ), there were 24 patients with the right coronary artery as the infarct related vessel in whom the ECG test was negative, but six of these patients (25\%) had a falsely negative test. Among patients with the left anterior descending coronary artery as the infarct related vessel, 19 had a negative ECG test, but this was falsely negative in just two $(11 \%)$.

RESCUE ANGIOPLASTY AND OUTCOME

The flow in the infarct related vessel is shown in table 7 . Fifty two patients had TIMI 3 flow on the first injection of contrast. A further seven patients achieved TIMI 3 flow by the end of the diagnostic angiogram. One of the 52 patients with initial TIMI 3 flow underwent percutaneous transluminal coronary angioplasty (PTCA) because the severity of the underlying coronary artery stenosis was considered highly likely to lead to reinfarction, but the other 58 patients with TIMI 3 flow by the end of the procedure did not undergo PTCA.

Of the 41 patients without TIMI 3 flow by the end of the coronary angiogram, rescue angioplasty was attempted on 36 occasions. In this group, final flow in the infarct related vessel was TIMI 3 in 30 patients, TIMI 2 in two, TIMI 1 in one, and TIMI 0 in three. Rescue angioplasty was not attempted in five patients: one patient with TIMI 2 flow but who was pain free and allergic to aspirin; one patient with an occluded vessel who was 12 hours into the myocardial infarction at the time of the diagnostic catheter and who was pain free and haemodynamically stable; one patient with severe triple vessel disease in whom the infarct related vessel could not be identified with certainty (but retrospectively was felt to be the circumflex artery); one patient with a proximally occluded right coronary artery but who was pain free and had evidence of collateral filling to the distal vessel; and one patient who was pain free with TIMI 2 flow and unfavourable anatomy for intervention.

Of the 52 patients who had TIMI 3 flow at the first contrast injection, six $(11.5 \%)$ sustained reinfarction requiring repeat coronary angiography and angioplasty during the same hospital admission; four required repeat coronary angiography proceeding to angioplasty for postinfarct angina; and two patients who had been discharged re-presented within 10 days of the original presentation with reinfarction and were treated by coronary angioplasty to the coronary artery lesion identified on the original coronary angiogram. Thus 12 of the 52 patients with TIMI 3 flow following thrombolytic treatment $(23.1 \%)$ required intervention for reinfarction or postinfarct angina within 10 days of the original presentation. Among the group leaving the cardiac catheter laboratory with TIMI 3 flow after angiography (59), there were three additional patients who reinfarcted during the hospital admission. Thus the reinfarction rate or requirement for clinically driven PTCA among the group with TIMI 3 flow following coronary angiography alone was 15 of 
Table 7 Numbers of patients with each grade of TIMI flow during catheter laboratory procedure

\begin{tabular}{llll}
\hline & $\begin{array}{l}\text { Flow at first } \\
\text { contrast } \\
\text { injection }\end{array}$ & $\begin{array}{l}\text { Flow after } \\
\text { completion of } \\
\text { angiogram }\end{array}$ & $\begin{array}{l}\text { Flow at end of } \\
\text { laboratory procedure } \\
\text { (including intervention } \\
\text { if performed) }\end{array}$ \\
\hline TIMI 0 & 35 & 31 & 5 \\
TIMI 1 & 1 & 1 & 1 \\
TIMI 2 & 12 & 9 & 5 \\
TIMI 3 & 52 & 59 & 89 \\
\hline
\end{tabular}

$59(25.4 \%)$. There were no deaths among these 15 patients.

Among the whole cohort of patients, six underwent coronary artery bypass grafting (CABG) before discharge. The in-hospital mortality among the patients with initial TIMI 3 flow (52) was 3.8\% and for those achieving TIMI 3 flow by the end of the procedure (59), $3.4 \%$. Among the patients with < TIMI 3 flow at initial angiography (48), the in-hospital mortality was $12.5 \%$. Among those with $<$ TIMI 3 flow after angiography (41), the in-hospital mortality was $14.6 \%$ (of the five patients not offered a rescue angioplasty, two died; of the 36 offered a rescue angioplasty, four died). The in-hospital mortality rate for the whole cohort was $8 \%$.

\section{Discussion}

LIMITATIONS OF THROMBOLYTIC TREATMENT This study confirms the limitations of thrombolytic treatment. Not only did $48 \%$ of our patients fail to achieve the desired TIMI 3 flow two hours after the initiation of thrombolysis, but almost one quarter of patients in whom angiographic evidence of TIMI 3 flow was achieved following thrombolysis alone sustained reinfarction or required PTCA for postinfarction angina within 10 days.

PREVIOUSLY DESCRIBED ECG CRITERIA FOR

DETECTION OF FAILED REPERFUSION

The aim of this study was to see whether a universally available and applicable ECG method could identify patients with inadequate antegrade flow in the infarct related vessel (failed thrombolysis), which is associated with increased mortality following acute myocardial infarction. It has been known for several years that ST segment resolution is seen with reperfusion in the infarct related vessel, ${ }^{56}$ and several relatively complex electrocardiographic methods for the detection of failed reperfusion were described subsequently. However, the design of some of these studies is flawed. In addition, many of the techniques described are impractical because they require very frequent recording of static ECGs, continuous ST segment monitoring, or detailed analysis.

Some previous studies recording the degree of ST segment resolution apparent on two or more ECGs recorded at predetermined time intervals should be interpreted with caution, given that the final ECG assessment was performed after, not before, coronary angiography. ${ }^{78}$ In our study, seven of 100 patients developed normal flow with the act of coronary angiography itself. Thus the very first angiographic appearances should be consid- ered. In addition, the ECG that will be used to estimate antegrade flow should be performed immediately before angiography.

Other studies recording the degree of ST segment resolution on two or more ECGs recorded at predetermined time intervals cannot be relied upon for the assessment of early arterial patency because coronary angiography was performed many hours, or even days, after thrombolysis was given. ${ }^{9-11}$

It seems logical that continuous ECG monitoring would be a superior technique to the recording of static ECGs, and this technique has been quite exhaustively investigated. ${ }^{12-16}$ Veldkamp and colleagues reported that continuous ST segment monitoring was at least as accurate as the most accurate of a number of static electrocardiographic methods, ${ }^{17}$ and Zabel and colleagues found that the use of two static ECGs before and two hours after thrombolytic treatment had the same predictive value as continuous Holter monitoring with respect to thrombolysis induced coronary artery reperfusion. ${ }^{18}$ Some investigators have described very specific and sensitive methods of detecting arterial patency using continuous ECG monitoring. For example, in a study of 38 patients Fernandez and colleagues reported that ST segment reduction of $50 \%$ or more in a single lead reflecting the infarct zone could predict arterial patency 60 minutes after thrombolysis with a sensitivity and specificity of $96 \%$ and $94 \%$, respectively. ${ }^{19}$ These investigators showed that analysis of ST segment shift by comparison to the peak ST segment elevation produces significantly different results when the ST segment shift is compared to the initial ST segment elevation. In their study, the sensitivity of $\geqslant 50 \%$ ST segment reduction by comparison to the peak ST segment elevation as a marker for TIMI 2 or 3 flow was $96 \%$ when the ST segment in the worst lead was analysed. However, the same degree of ST segment reduction by comparison with the initial ECG produced a sensitivity of just $64 \%$ for TIMI 2 or 3 flow. It should be noted that analysis of Holter recordings in that study was performed retrospectively and not in real time, which is essential for identifying patients who may benefit from further intervention when thrombolytic treatment has failed. Finally the authors recommended that the non-invasive prediction of arterial patency requires continuous ST segment monitoring, or ECGs recorded at least as often as every 10 minutes, and this is unlikely to be achieved in most CCUs.

Other ECG techniques have also been described. The use of the summed ST segment elevation in all leads and measurement of the degree of resolution has been reported to have a high degree of sensitivity and specificity for patency assessment. ${ }^{20}$ However, the measurement of ST segment shift in all leads on a standard 12 lead ECG is impractical, especially as it requires measurement of small deviations in leads which do not reflect the infarct zone. 
CURRENT STUDY

In our study, we assessed the ability of several simple ECG criteria to detect inadequate flow in the infarct related vessel. The best ECG indicator for assessing the absence of TIMI 3 flow was failure of the ST segment elevation in the worst lead to fall by $50 \%$ in the absence of an accelerated idioventricular rhythm. This is also the simplest and most easily measured test among those we performed. We acknowledge that the sensitivity of this test for detecting flow less than TIMI 3 is not $100 \%$, which is to be expected. In practice, this means that some patients with ST segment resolution might be incorrectly classified as having reperfused. There is evidence from a non-angiographic study $^{21}$ that ST segment resolution as early as 60 minutes after the initiation of thrombolytic treatment identifies a low risk group of patients, even though it is reasonable to assume from our own study that some of these patients will not have normal antegrade flow in the infarct related vessel. This may occur in some patients if the infarct related vessel is well collateralised. Two of the nine patients in whom we incorrectly diagnosed successful reperfusion on the basis of ST segment resolution had detectable collateral flow to the distal bed of the occluded infarct related vessel, although collateral flow may have been present in the others but not angiographically detectable.

The failure of the ST segment elevation in the worst lead two hours after the initiation of thrombolysis to fall by $\geqslant 50 \%$ and the absence of accelerated idioventricular rhythm at this time is, however, a specific marker of inadequate (<TIMI 3) flow. Patients with these ECG features are highly likely to have either complete arterial occlusion or TIMI 1/TIMI 2 flow, and should be considered at high risk for further adverse cardiac events.

The sensitivity and negative predictive values of all our ECG tests are improved by considering adequate antegrade flow as either TIMI 2 or TIMI 3 flow, but this is at the expense of a reduction in specificity and positive predictive value. In a study linking the GUSTO-1 angiographic substudy and mortality outcomes, ${ }^{22}$ the 30 day mortality for TIMI 2 flow at 90 minutes was intermediate between that of TIMI $0 / 1$ flow and that of TIMI 3 flow, but TIMI 2 flow was not associated with a significant survival advantage compared with TIMI grade 0 or 1 . However, these data should be interpreted with caution. First, a single angiogram does not take into account the dynamic nature of coronary flow, so patients with TIMI 2 flow may have gone on to develop TIMI 3 flow. Second, a larger study may have detected a significant mortality benefit with the presence of TIMI 2 flow compared with TIMI 0/1 flow. Perhaps this is why patency is often described as the presence of TIMI 2 or TIMI 3 flow. We have included data for TIMI 2 and TIMI 3 flow, but believe that an ECG rule which detects the presence or absence of TIMI 2 flow in patients with acute myocardial infarction is only useful in clinical practice if TIMI 2 flow reliably progresses to TIMI 3. As this has not yet been demonstrated, the detection of failure to achieve TIMI 3 flow best identifies the high risk patient.

Including the presence or absence of chest pain at the time of the two hour ECG would further affect the sensitivity and specificity of our ECG test. We did not include chest pain as a criterion for failed thrombolysis because in our experience TIMI 3 flow can be associated with a persistent ache, TIMI 0 flow can be pain free following opiates, and there is often difficulty in distinguishing ischaemic and pericarditic pain in patients who present after six hours. The result of the test would also depend on whether positive ECG criteria and chest pain are required or just the presence of one of them.

Including all accelerated idioventricular rhythms occurring in the two hours following the initiation of thrombolysis may increase specificity of the ECG criteria used in this study. However, the sensitivity of the test is unlikely to be affected as it has previously been reported that the absence of accelerated idioventricular rhythm does not indicate persistent arterial occlusion. ${ }^{23}$ In practice, only a small number of patients (just two in our study) will have an accelerated idioventricular rhythm captured on the two hour ECG. However, we could not include all cases of post-thrombolysis accelerated idioventricular rhythm in this analysis because many such reperfusion arrhythmias are too slow to trigger rate alarms on the CCU and often go undetected by busy nursing staff.

\section{STUDY LIMITATIONS}

The recording of static ECGs does not allow one to predict whether persistent ST segment elevation on a later ECG is caused by failure of reperfusion or by reperfusion injury, which can result in gross ST segment elevation. ${ }^{24}{ }^{25}$ Shah and colleagues showed that over $50 \%$ of patients have transient increases in ST segment elevation before final resolution, and emphasised the need for continuous ECG monitoring in order to determine accurately the point of reperfusion. ${ }^{26}$ Thus the use of two static ECGs does not take into account the dynamic nature of ST segment shifts following acute myocardial infarction.

In addition, there is no consensus over when the second of a pair of static ECGs performed either side of the initiation of thrombolysis should be recorded. It has been suggested that a second ECG be performed 40 minutes after the onset of thrombolytic treatment and a third be performed after 120 minutes to assess ST segment stability. ${ }^{27}$ It could be argued that further static ECGs should be performed, as further ST segment shifts between six and 24 hours are associated with a worse prognosis. ${ }^{28}$ However, evidence from a study of unselected patients suggests that ST segment analysis on an ECG 60 minutes after the initiation of thrombolysis is just as capable of identifying high risk patients as ECGs at two or three hours. ${ }^{21}$ In this study, the 36 day mortality for patients with $<50 \%$ resolution of the ST segment elevation in the worst lead was $18.2 \%$ at 60 minutes, $16.7 \%$ at 90 minutes, and 
$20.8 \%$ at 180 minutes. In future, this may precipitate a move towards additional treatment (for example, rescue angioplasty) as early as 60 minutes after thrombolytic treatment is deemed to have failed.

We chose a method based on the recording of two static ECGs two hours apart for three reasons. First, continuous ECG monitoring is not currently available in our CCU. Second, it is known that a significant number of patients reperfuse between the first and second hours after initiation of thrombolysis. By two hours, $52 \%$ of our patients had achieved TIMI 3 flow. In the angiographic substudy of GUSTO- $1,{ }^{2}$ just $29 \%$ of those receiving intravenous streptokinase and subcutaneous heparin had achieved TIMI 3 flow by 90 minutes. Therefore, a later ECG for the non-invasive assessment of antegrade flow is likely to prevent an excess number of unnecessary coronary angiograms. Third, the two hour ECG still allows a second intervention to take place, if this is considered appropriate, before irreversible myocardial necrosis occurs.

We did not look specifically at $\mathrm{T}$ wave inversion as a marker of normal antegrade flow, although this has previously been examined. ${ }^{29}$ However, that study used early $\mathrm{T}$ wave inversion $(<24$ hours after the administration of thrombolytic treatment) as a marker of normal antegrade flow assessed angiographically within 72 hours of admission. Thus the results cannot be extrapolated to the detection of normal flow in an infarct related vessel within the first few hours after administration of thrombolytic treatment, at a stage when further intervention may prevent irreversible myocardial necrosis.

Finally, although our ECG method was designed to detect < TIMI 3 flow in the infarct related vessel, there is evidence to show that tissue perfusion at a cellular level may be abnormal despite the presence of TIMI 3 flow in this vessel. ${ }^{30}$ In clinical practice, persistent ST segment elevation may be seen following acute infarction angioplasty despite the restoration of normal flow in the epicardial vessel. It is possible that in the future more sophisticated techniques, such as contrast echocardiography, will allow prediction of reperfusion at the tissue level, rendering the degree of TIMI flow in the epicardial vessel and the ST segment changes on the ECG irrelevant. Until such time, however, the goal of reperfusion treatment is the presence of normal antegrade flow in the infarct related vessel. At present, therefore, the aim of non-invasive techniques to detect failed reperfusion should be to detect less than adequate flow in the infarct related vessel.

CONCLUSIONS

The simple, widely applicable ECG criteria described in our study can be interpreted without recourse to specialised equipment and have an important role in detecting patients at high risk of persistent arterial occlusion following thrombolytic treatment. Even though there is a move towards primary angioplasty for the treatment of acute myocardial infarction, thrombolysis is still the mainstay of treatment in most centres, but there is no consensus of opinion about the management of those patients in whom thrombolytic treatment is unsuccessful. Non-invasive criteria to detect these patients will be required before trials can be performed. From our study, patients with $<50 \%$ resolution of the ST elevation in the worst lead and no accelerated idioventricular rhythm two hours after the initiation of thrombolytic treatment have an $87 \%$ chance that inadequate (< TIMI 3) flow is present in the infarct related vessel. It has been suggested that a one hour ECG can reliably detect a high risk group of patients, but whether rescue angioplasty is appropriate at that stage would depend on whether ST segment analysis can reliably predict flow in the infarct related vessel. Our current strategy is to offer rescue angioplasty as soon as the two hour ECG suggests persistent arterial occlusion, but we accept that further trials are required to demonstrate the superiority of this approach over other treatment options for failed thrombolysis, such as repeat thrombolytic treatment.

1 Fibrinolytic Therapy Trialists' (FTT) Collaborative Group. Indications for fibrinolytic therapy in suspected acute myocardial infarction: collaborative overview of early mortality and major morbidity results from all randomised trials of more than 1000 patients. Lancet 1994;343:311-22.

2 The GUSTO Angiographic Investigators. The effects of tissue plasminogen activator, streptokinase, or both on coronary artery patency, ventricular function and survival after acute myocardial infarction. N Engl F Med 1993;329:161522

3 The GUSTO Investigators. An international trial comparing four thrombolytic strategies for acute myocardial infarction. N Engl f Med 1993;329:673-82.

4 The TIMI Study Group. The thrombolysis in myocardial infarction (TIMI) trial: phase 1 findings. $N$ Engl $\mathcal{f}$ Med 1985;312:932-6.

5 Blanke H, Scherff F, Karsch KR, et al. Electrocardiographic changes after streptokinase-induced recanalization in patients with acute left anterior descending artery obstruction. Circulation 1983;68:406-12.

6 Hackworthy RA, Vogel MB, Harris PJ. Relationship between changes in ST segment elevation and patency of the infarct-related coronary artery in acute myocardial infarction. Am Heart $\mathcal{F}$ 1986;112:279-84.

7 Hogg KJ, Hornung RS, Howie CA, et al. Electrocardiographic prediction of coronary artery patency after thromgraphic prediction of coronary artery patency after throm-
bolytic treatment in acute myocardial infarction: use of the ST segment as a non-invasive marker. Br Heart f 1988;60: 275-80.

8 Saran RK, Been M, Furniss SS, et al. Reduction in ST-segment elevation after thrombolysis predicts either coronary reperfusion or preservation of left ventricular function. Br Heart $\mathcal{F}$ 1990;64:113-17.

9 Barbash GI, Roth A, Hod H, et al. Rapid resolution of ST elevation and prediction of clinical outcome in patients undergoing thrombolysis with alteplase (recombinant tissue-type plasminogen activator): results of the Israeli study of early intervention in myocardial infarction. $\mathrm{Br}$ Heart f 1990;64:241-7.

10 Richardson SG, Morton P, Murtagh JG, et al. Relation of coronary patency and left ventricular function to electrocardiographic changes after streptokinase during acute myocardial infarction. Am f Cardiol 1988;61:961-5.

11 Nicolau JC, Lorga AM, Garzon SAC, et al. Clinical and Nicolau JC, Lorga AM, Garzon SAC, et al. Clinical and
laboratory signs of reperfusion: are they reliable? Int $f$ Cardiol 1989;25:313-20.

12 Krucoff MW, Green CE, Satler LF, et al. Noninvasive detection of coronary artery patency using continuous STsegment monitoring. Am f Cardiol 1986;57:916-22.

13 Krucoff MW, Croll MA, Pope JE, et al. Continuously updated 12-lead ST-segment recovery analysis for myocardial infarct artery patency assessment and its correlation with multiple simultaneous early angiographic observations. Am $\mathcal{F}$ Cardiol 1993;71:145-51.

14 Krucoff MW, Croll MA, Pope JE, et al. Continuous 12-lead ST-segment recovery analysis in the TAMI 7 study. Performance of a noninvasive method for real-time detection of failed myocardial reperfusion. Circulation 1993;88:437-46.

15 Ottani F, Galvani M, Coccolini S, et al. Non-invasive assessment of reperfusion of the infarct-related artery during coronary thrombolysis and its relation with left ventricular coronary thrombolysis and its relation with left

16 Klootwijk P, Langer A, Meij S, et al. Non-invasive prediction of reperfusion and coronary artery patency by continuous ST segment monitoring in the GUSTO-I trial. Eur Heart $\mathcal{F}$ 1996;17:689-98. 
17 Veldkamp RF, Green CL, Wilkins ML, et al. Comparison of continuous ST-segment recovery analysis with methods for noninvasive patency assessment during acute myocardial infarction. Thrombolysis and angioplasty in myocardial infarction (TAMI) 7 Study Group. Am 7 Cardiol 1994;73:1069-74.

18 Zabel M, Hohnloser SH, Parussel A, et al. ST segment analysis for assessment of coronary artery patency: comparison of surface ECG and Holter recordings. Eur Heart F 1992;13:1619-25.

19 Fernandez AR, Sequeira RF, Chakko S, et al. ST segment tracking for rapid determination of patency of the infarct-related artery in acute myocardial infarction. $7 \mathrm{Am}$ Coll Cardiol 1995;26:675-83.

20 Clemmensen P, Ohman M, Sevilla DC, et al. Changes in standard electrocardiographic ST-segment elevation predictive of successful reperfusion in acute myocardiol infe-

dictive of successful reperfusion in acute myocardial infarc-
tion. Am 7 Cardiol 1990;66:1407-11.

Change in ST segment elevation 60 minutes after thrombolytic initiation predicts clinical outcome as accurately as later changes. Heart 1997; 78:465-71.

22 Simes RJ, Topol EJ, Holmes DR, et al, for the GUSTO-1 Investigators. Link between the angiographic substudy and mortality outcomes in a large randomized trial of myocardial reperfusion. Circulation 1995;91:1923-8.

23 Doevendans PA, Gorgels AP, van der Zee R, et al. Electrocardiographic diagnosis of reperfusion during thrombolytic therapy in acute myocardial infarction. $A m \Im$ Cardiol 1995;75:1206-10.
24 Dissmann R, Linderer T, Goerke $M$, et al. Sudden increase of the ST segment elevation at time of reperfusion predicts extensive infarcts in patients with intravenous thrombolysis. Am Heart F 1993;126:832-9.

25 Kondo $\mathrm{M}$, Tamura $\mathrm{K}$, Tanio $\mathrm{H}$, et al. Is ST segment re-elevation associated with reperfusion an indicator of marked myocardial damage after thrombolysis? f Am Coll Cardiol 1993;21:62-7.

26 Shah PK, Cercek B, Lew AS, Ganz W. Angiographic validation of bedside markers of reperfusion. $\mathcal{F} \mathrm{Am}$ Coll Cardiol 1993;21:55-61

27 Krucoff MW, Green CL, Trollinger KM, et al. Temporal distribution of important ECG information in patients with MI: when should you take the next ECG after lytics? [abstract] f Am Coll Cardiol 1997;29:131.

28 Langer A, Krucoff MW, Klootwiik P, et al. Prognostic significance of ST segment shift early after resolution of ST elevation in patients with myocardial infarction treated with thrombolytic therapy: the GUSTO-I ST segment monitoring substudy. 7 Am Coll Cardiol 1998;31:783-9.

29 Matetzky S, Barabash GI, Shahar A, et al. Early T wave inversion after thrombolytic therapy predicts better coronary perfusion: clinical and angiographic study. $7 \mathrm{Am}$ Coll Cardiol 1994;24:378-83.

30 Ito H, Tomooka T, Sakai N, et al. Lack of myocardial perfusion immediately after successful thrombolysis: a predictor of poor recovery of left ventricular function in anterior myocardial infarction. Circulation 1992;85:1699-705.

\section{IMAGES IN CARDIOLOGY}

\section{Endomyocardial fibrosis associated with antiphospholipid syndrome}

A 50 year old woman presented with axillary vein thrombosis and was diagnosed as having the antiphospholipid syndrome. The patient also had hypereosinophilia and developed features of severe right heart failure. A transthoracic echocardiogram revealed features characteristic of hypereosinophilic cardiomyopathy leading to endomyocardial fibrosis. Various cardiac manifestations associated with antiphospholipid syndrome have been reported, including dilated cardiomyopathy, mural thrombi, valvar heart disease, nonbacterial vegetations, and pericardial effusion. However, the association between endomyocardial fibrosis and antiphospholipid syndrome has not been reported before.

The apical four chamber transthoracic echocardiogram shows endomyocardial fibrosis. The infiltration has characteristically involved the apical segments of both right (RV) and left (LV) ventricles leading to virtual obliteration of the apices in systole (top, arrows). The right ventricle cavity is very small and the right atrium (RA) is very enlarged. The diastolic view (bottom) reveals tethering of the apical interventricular septum. The basal segment of the interventricular septum is bowing to the left ventricle because of the raised intracavity pressure in the right ventricle during diastole.
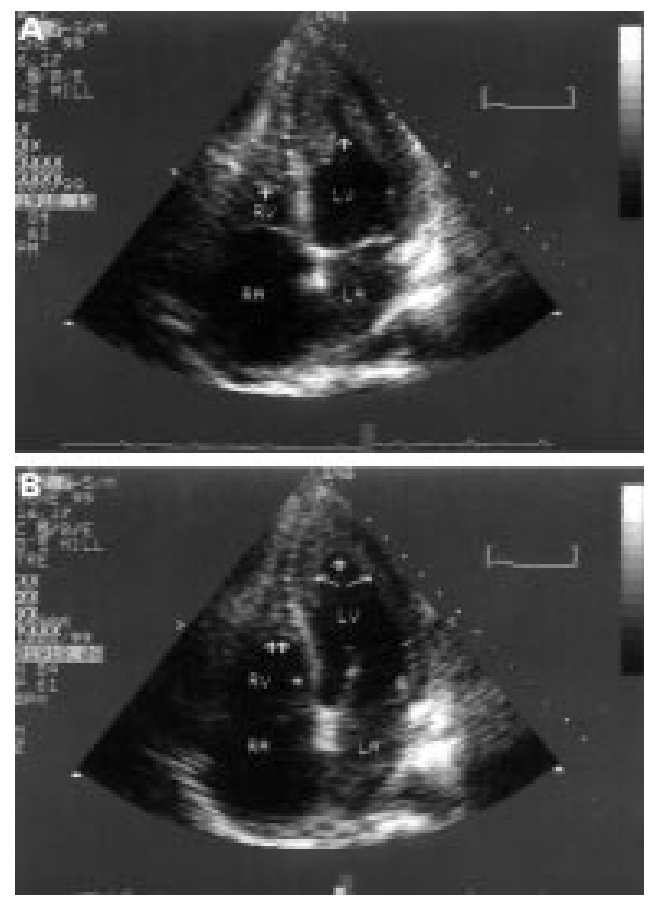

T AZEEM $M$ VASSALLO

N J SAMANI 